\title{
The ESR in the diagnosis and management of the polymyalgia rheumatica/giant cell arteritis syndrome
}

\author{
M. E. ELLIS ANDS.RALSTON \\ From the Royal Infirmary, Aberdeen
}

\begin{abstract}
SUMMARY A review of 80 patients with the polymyalgia rheumatica/giant cell arteritis (PMR/GCA) syndrome has revealed that the erythrocyte sedimentation rate (ESR) is normal in $22.5 \%$ of cases at presentation. Too much reliance on the ESR as a screening test led to delay in diagnosis in 10 patients. Serious complications occurred in 4 patients with a normal or minimally raised ESR. Analysis of follow-up data at 4 weeks showed no significant correlation between change in the ESR and change in symptoms, and at subsequent clinical attendances symptoms did not consistently parallel the ESR. Our results cast serious doubts on the use of the ESR as an entirely reliable diagnostic and therapeutic aid in the PMR/GCA syndrome.
\end{abstract}

Considerable emphasis has been placed on the ESR in the polymyalgia rheumatica/giant cell arteritis (PMR/GCA) syndrome. Most workers consider a markedly raised ESR to be essential for the diagnosis. ${ }^{1-3}$ The raised ESR is also accepted as a reflection of disease activity and consequently it is used to regulate corticosteroid dosage. ${ }^{4}$ Conversely a normal ESR has been taken to exclude the diagnosis ${ }^{3}$ or to imply quiescence of disease activity, despite reported cases of PMR/GCA with a normal ESR. ${ }^{5}$

We have undertaken a retrospective study of the ESR in patients admitted to the Aberdeen Hospitals with a diagnosis of PMR/GCA. In this study the relationship of the ESR to clinical findings at various times in the disease process is reported and an assessment of the role of the ESR in diagnosis and management is presented.

\section{Patients and methods}

Records were obtained by using the International Classification of Diseases index number for PMR/GCA over the period 1968-78. Of the 97 case records requested 6 were rejected because of an error in diagnostic classification and a further 11 cases because they did not satisfy fully our diagnostic criteria. Both the typed and hand-written entries in the remaining 80 case notes were scrutinised, and data were obtained from a total of 758 hospital

Accepted for publication 19 March 1982.

Correspondence to Dr S. Ralston, University Department of Medicine, Royal Infirmary, Glasgow G4 OSF. attendances. Duration of follow-up varied from 4 weeks to 10 years.

The diagnostic criteria are shown in Table 1. Patients were accepted if criteria 1-3 were present plus any 3 of criteria 5-10 or criterion 4 . Patients with evidence of myeloma, rheumatoid arthritis, systemic lupus erythematosis, polymyositis, and disseminated malignancy were excluded. The ESR in all cases was performed by the Westergren method. ${ }^{6}$

We made particular note of initial presentation, the time at which a trial of steroid therapy was thought to be indicated (diagnosis), and follow-up after 4 weeks on corticosteroid therapy. In assessing response to treatment the patients were grouped by symptom type as follows: (PMR), proximal muscle pain and stiffness; (GCA), headache, jaw claudication, scalp tenderness, and systemic weight loss, anorexia, malaise. A graded clinical score was em-

Table 1 Diagnostic criteria

\begin{tabular}{|c|c|}
\hline 1. & Age greater than 55 years \\
\hline 2. & $\begin{array}{l}\text { Positive response within } 48 \text { hours to corticosteroid } \\
\text { therapy }\end{array}$ \\
\hline 3. & Length of history greater than 2 weeks \\
\hline 4. & Positive temporal artery biopsy \\
\hline 5. & $\begin{array}{l}\text { Proximal, symmetrical girdle or upper arm muscle } \\
\text { pain } \pm \text { stiffness } \pm \text { tenderness }\end{array}$ \\
\hline 6. & Jaw claudication \\
\hline 7. & $\begin{array}{l}\text { Clinical abnormality of a temporal artery (tenderness, } \\
\text { thickening, redness) }\end{array}$ \\
\hline 8. & $\begin{array}{l}\text { Systemic symptoms or signs (malaise, anorexia, weight } \\
\text { loss, anaemia, pyrexia) }\end{array}$ \\
\hline 9. & Temporal headache \\
\hline 10. & Visual disturbance (loss, diplopia, blurring) \\
\hline
\end{tabular}


ployed to assess disease activity (0: asymptomatic to 4 : increasingly severe). Correlation coefficients were obtained by means of Pearson's product moment correlation method.

\section{Results}

Clinical features at diagnosis. These are summarised in Table 2.

ESR at presentation. A total of 18 patients $(22.5 \%)$ presented with an ESR of $<30 \mathrm{~mm} / \mathrm{h}$ (Fig. 1). Of this group 8 were diagnosed immediately on clinical grounds alone and therapy with corticosteroids was begun.

In the 10 patients with an ESR $<30 \mathrm{~mm} / \mathrm{h}$ not diagnosed immediately on clinical grounds there was a mean interval of 106 days from presentation or institution of corticosteroid therapy. This compares with an interval of 35 days in those presenting with an ESR $>30 \mathrm{~mm} / \mathrm{h}$.

ESR and clinical features. In Table 3 correlation coefficients are shown between ESR at presentation and other variables. Statistical analysis confirmed a highly significant correlation between ESR and anaemia at both presentation and diagnosis $(p<0.001)$. There was no significant correlation between presenting ESR and subsequent development of visual loss or any other variable. Four patients in the series developed visual loss with either a normal or slightly raised ESR at the time of visual loss (ESR $=11,21,30,40$ ).

ESR and management of patients. On initiation of corticosteroid therapy all the patients had rapid relief of symptoms and the ESR also tended to fall (Fig. 1). When the degree of symptomatic improvement at 4 weeks as assessed by clinical score was compared with the numerical change in the ESR, however, we found no significant correlation $(r=0 \cdot 088)$. On analysis of follow-up data on a further 678 atten-

Table 2 Clinical features at diagnosis

\begin{tabular}{lcc}
\hline & \multicolumn{2}{c}{ Number of patients } \\
\cline { 2 - 3 } & Male & Female \\
\hline Total & 19 & 61 \\
Predominately PMR & 0 & 4 \\
Predominantly GCA & 8 & 31 \\
Mixed & 11 & 26 \\
Systemic symptoms & 11 & 33 \\
Number of biopsies & 16 & 46 \\
Positive biopsies & 5 & 28 \\
Anaemia (Hb<10.5 g/dl) & 5 & 16 \\
Jaw claudication & 6 & 9 \\
Pain on swallowing & 3 & 6 \\
Visual loss & 4 & 13 \\
Visual disturbance & 3 & 8 \\
Average age of patients & $74(\mathrm{SD}=8 \cdot 5)$ & $69(\mathrm{SD}=7 \cdot 6)$ \\
\hline
\end{tabular}

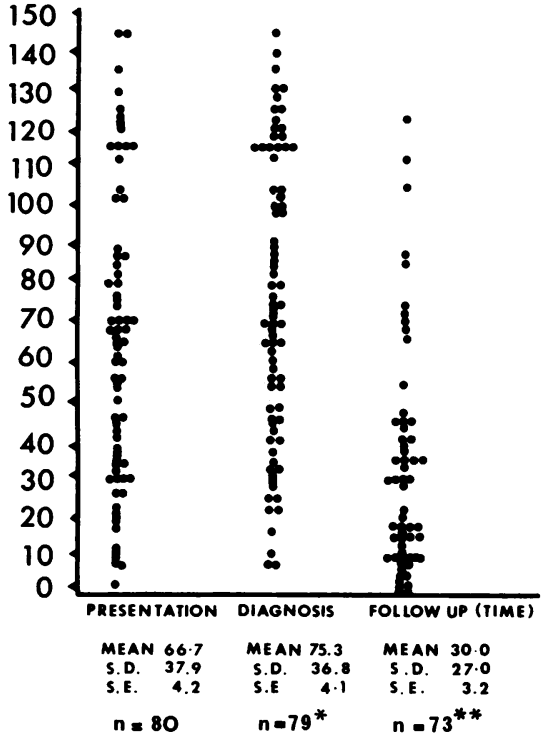

*ESR on one occasion was not repeated at diagnosis.

Fig. 1 ESR at presentation, diagnosis, and follow-up

Table 3 Correlation coefficients

\begin{tabular}{lc}
\hline & Presenting ESR \\
\hline Age & $0 \cdot 073$ \\
Sex & $0 \cdot 104$ \\
Duration of symptoms & -0.092 \\
PMR symptoms & $-0 \cdot 111$ \\
GCA symptoms & $-0 \cdot 066$ \\
Systemic symptoms & $0 \cdot 129$ \\
Haemoglobin & $0 \cdot 637^{*}$ \\
Visual loss & $0 \cdot 158$ \\
Visual disturbance & $0 \cdot 132$ \\
Positive biopsy & $0 \cdot 194$ \\
\hline
\end{tabular}

${ }^{*} \mathrm{p}<0 \cdot 001$.

dances at outpatient clinics there did not appear to be a universally accepted policy for the adjustment of corticosteroid therapy, and little emphasis was given to other medical conditions known to affect the ESR. ${ }^{7}$ Adjustments in corticosteroid therapy were made on $191(28.1 \%)$ of the above attendances owing to changes in the patients' symptoms, the ESR, or both. Symptoms and ESR paralled each other on only $44(23 \%)$ of these occasions. In the remainder physicians varied in their treatment policy when an asymptomatic patient presented with a raised ESR or vice versa. On $77(40 \%)$ occasions therapy was altered on the basis of the ESR alone. There were 47 documented instances in 37 symptomatic patients of intercurrent illness-mainly urinary and respiratory 
infections. The ESR was raised $(>30 \mathrm{~mm} / \mathrm{h})$ in 41 of these instances but only on one occasion was the rise attributed to the intercurrent illnesses. In the remainder the raised ESR was thought to reflect an exacerbation of the PMR/GCA syndrome, and therapy was adjusted on this basis.

\section{Discussion}

Standard textbooks ${ }^{8}{ }^{9}$ and clinical reviews ${ }^{1-4}$ emphasise that the ESR is almost invariably raised in the PMR/GCA syndrome, values in excess of $50 \mathrm{~mm} / \mathrm{h}$ being commonly found, ${ }^{1-4}$ and this level is said by some to be a sine qua non for the diagnosis. ${ }^{1}$ However, an 'elevated' ESR is not clearly or consistently defined in the literature. Westergren's original work put the upper limits of normal as $3 \mathrm{~mm} / \mathrm{h}$ for males and $7 \mathrm{~mm} / \mathrm{h}$ for females. The accepted limit of normal has risen considerably since then. In a large series of 2500 healthy men and women it was found that the upper limit of normal for the ESR above the age of 50 years was $20 \mathrm{~mm} / \mathrm{h}$ for men and $30 \mathrm{~mm} / \mathrm{h}$ for women. ${ }^{10}$ Values between 20 and 40 are difficult to interpret, ${ }^{11}$ but we have adopted a value of $>30 \mathrm{~mm} / \mathrm{h}$ as 'elevated'. Recently others have used this value of $>30 \mathrm{~mm} / \mathrm{h}$ as a diagnostic criterion for PMR/GCA. ${ }^{12}$ By this definition a normal ESR was found in $22.5 \%$ of the patients at presentation. This is a much higher incidence than in other series. ${ }^{43-15}$ It may be argued that the heterogeneous selection of patients in our series may have influenced the ESR, as it has been claimed that patients with GCA syndrome alone tend to have a higher ESR. ${ }^{13}$ We have failed to show any significant difference in the ESR for different symptom types, however (Table 3).

A normal ESR in patients with otherwise classical PMR/GCA tended to mislead physicians, resulting in a serious delay in diagnosis, consistent with the commonly held belief that the diagnosis of PMR/GCA in untenable in the absence of a raised ESR. There was no significant correlation between ESR at presentation and the subsequent development of visual loss. The ESR cannot therefore be used to predict which patients will go on to develop this complication. Furthermore 3 patients in our series had a normal ESR at the time of visual loss, and in one the ESR was only slightly raised at $40 \mathrm{~mm} / \mathrm{h}$.

On occasions when an asymptomatic patient presented with a raised ESR, or the converse, the physician's treatment policy varied between treating the patient's symptoms irrespective of the ESR and directing treatment at the ESR alone. The literature is also divided on this point, however. Wadman and Werner $^{16}$ noted that, although nonsteroidal antiinflammatory drugs were successful in relieving symptoms of polymylagia rheumatica, they did not prevent the development of visual complications.
The same hazard was noted with doses of steroids insufficient to suppress the ESR. ${ }^{17}$ More recently, however, it has been reported that after the initial period steroid dosage may be kept at the minimum required for symptomatic relief, irrespective of the ESR, without the development of complications. ${ }^{15}$ None of the patients in our series developed visual loss after the initial 48 hours on corticosteroid therapy. Doubts have been cast on the usefulness of the ESR in the diagnosis of other disease processes. ${ }^{18}$ Perhaps the difficulties associated with performing the test uniformly and the presence of several different factors affecting the ESR at any one time ${ }^{11}$ tend to make it an inherently inaccurate diagnostic test.

From our data it is evident that the ESR is not an entirely reliable guide in the diagnosis or monitoring of disease activity in the PMR/GCA syndrome, nor can it predict the development of complications.

We thank the Physicians Committee, Aberdeen Hospitals, for allowing us to study their patients.

\section{References}

1 Healey L A, Parker F, Wilske K R. Polymyalgia rheumatica and giant cell arteritis. Arthritis Rheum 1971; 14: 138-41.

2 Hunder G G, Allen G L. The relationship between polymyalgia rheumatica and temporal arteritis. Geriatrics 1973; 28: 134-42.

3 Huston K A, Hunder G G. Giant cell (cranial) arteritis: a clinical review. Am Heart J 1980; 100: 99-107.

4 Huston K A, Hunder G G, Lie J T, Kennedy R H, Elrebeck L R. Temporal arteritis. A 25 year epidermiological, clinical and pathologic study. Ann Intern Med 1978; 88: 162-7.

5 Bruk $M$ I. Articular and vascular manifestations of polymyalgia rheumatica. Ann Rheum Dis 1967; 26: 103-16.

6 Westergren A. Studies of the suspension stability of the blood in pulmonary tuberculosis. Acta Med Scand 1921; 54: 247.

7 Liljestrand A, Olhagen B. Persistently high erythrocyte sedimentation rate. Diagnostic and prognostic aspects. Acta Med Scand 1955; 151: 425-39.

8 Beeson P B, McDermott W, Wyngaarden J B, eds. Cecil: Textbook of Medicine. Philadelphia: Saunders, 1979.

9 Scott J T, ed. Copeman's Textbook of the Rheumatic Diseases. Edinburgh: Livingstone, 1978.

10 Bottiger L E, Svedberg C A. Normal erythrocyte sedimentation rate and age. $\mathrm{Br}$ Med J 1967; ii: 85-7.

11 Zacharski L R. The erythrocyte sedimentation rate. Br J Hosp Med 1976; 16: 53-62.

12 Jones J G, Hazleman B L. Prognosis and management of polymyalgia rheumatica. Ann Rheum Dis 1981; 40: 1-5.

13 Hamilton C R, Shelley W M, Tumulty P A. Giant cell arteritis: including temporal arteritis and polymyalgia rheumatica. Medicine 1971; 50: 1-27.

14 Fauchald P, Rygrold O, Oystese B. Temporal arteritis and polymyalgia rheumatica. Clinical and biopsy findings. Ann Intern Med 1972; 77: 845-52.

15 Graham E, Holland A, Avery A, Russel R W R. Prognosis in giant cell arteritis. $B r$ Med $J$ 1981; ii: 269-71.

16 Wadman B, Werner I. Therapeutic hazards of phenylbutazone and oxyphenbutazone in polymyalgia rheumatica. Lancet 1967 ; i: 597.

17 Kogstad O A. Polymylagia rheumatica and its relation to arteritis temporalis. Acta Med Scand 1965; 178: 591.

18 Anonymous. Sedimentation rate in malignancy. Lancet 1963; i: 94 . 